\section{A Formação do Enfermeiro Frente à Reforma Sanitária*}

\author{
Maria Cecilia Puntel de Almeida
}

\section{INTRODUÇÃO}

O relatório final da VIII Conferência Nacional de Saúde, ao apontar as modificações necessárias no setor saúde, ampliando o próprio conceito de saúde e sua correspondente ação institucional, impõe uma séria reflexão sobre a formação de Recursos Humanos para esie setor e, implicitamente, sobre a formação de Recursos Humanos em Enfermagem.

Este texto tem por objetivo fazer esta reflexão, buscando as relações entre as conclusões da VIII Conferência Nacional de Saúde, a Forçą de Trabalho em Enfermagem e o delineamento de uma política de Recursos Humanos em Enfermagem, com vistas à Reforma Sanitária.

Para esta reflexão utilizamos como documentos básicos, além do relatório final da VIII Conferência Nacional de Saúde: Nogueira, R.P. - Dinâmica do Mercado de Trabalho em Saúde no Brasil, 1970/1983; Brasília, OPS - Acordo MS, MPAS, MEC, MCT, 1986 e Conselho Federal de Enfermagem: O exercício da Enfermagem nas Instituições de Saúde no Brasil; 1982/1983 - Conselho Federal de Enfermagem, Associação Brasileira de Enfermagem, Rio de Janeiro, 1985.

Em seu relatório final, a VIII Conferência Nacional de Saúde assinala as vicissitudes que deram origem a um sistema de saúde onde, no setor privado, predominam interesses de empresários da área médico-hospitalar e, no setor público, o modelo é anárquico, pouco eficiente e eficaz, gerando descrédito junto à população.

Entre as causas que contribuem para este quadro, ali mencionadas, destacamos as seguintes: inadequada formação de Recursos Humanos, tanto em nível técnico quanto nos aspectos éticos e de consciência social, associada à sua utilização em condições insatisfatórias de remuneração e de trabalho. Acresce-se, ainda, a interferência clientilística no que se refere à contratação de pessoal.

\section{- A FORMAÇÃO DE TRABALHO EM SAÚdE}

Nogueira ${ }^{3}$, avaliando a força de trabalho em saúde faz algumas constatações que ressaltamos: o total da força de trabalho em saúde, em 1980, era de 1.233.008 trabalhadores, composta majoritariamente por profissionais de nível médio e elementar (cerca de 32\%). O setor absorve, portanto, uma extensa força de trabalho de baixa qualificação, utilizada em atividades auxiliares e de apoio.
* Contribuição de um grupo de enfermeiros-docentes da escola de enfermagem de Ribeirão PretoUSP, para a "Conferência Nacional de Recursos Humanos em Saúde'

Brastia-outubro de 1986

Semiramis Melani Mello Rocha, Elizabeth Laus, Dulce Maria Vendrúsculo de Freitas, Regina Aparecida Garcia Lima e Silvana Mishima 
A partir de 1964, os processos de urbanização e metropolização do espaço brasileiro criaram um forte movimento de terciarização da atividade econômica. Os serviços de saúde aparecem neste setor terciário da economia como importantes geradores de empregos de baixa qualificação, concorrendo com a indústria manufatureira e com o comércio varejista.

Os profissionais de nível superior ocupam $30 \%$ do total de pessoas ocupadas em atividades de saúde, onde $17 \%$ correspodem aos médicos e $2 \%$ aos enfermeiros. Os $70 \%$ restantes constituem-se por pessoal de nível médio e elementar, dentre eles $50 \%$ são profissionais de enfermagem. Este contingente é composto por três categorias distintas: Técnico, Auxiliar e Atendentes de Enfermagem.

Analisando o crescimento da força de trabalho em Enfermagem (dados COFEn/ABEn) constatamos que, entre $1956 \mathrm{e}$ 1983, ele se deu de forma diferenciada entre as várias categorias. Os Técnicos e Auxiliares creceram de forma mais acentuada que Enfermeiros e Atendentes, com o resultado das políticas educacionais de profissionalização de Técnicos de Nível Médio.

$\mathrm{Na}$ composição da força de trabalho em enfermagem, constituída por 304.287 pessoas, os Enfermeiros repesentam 8,5\%, os Técnicos de Enfermagen 6,6\%, os Auxiliares de Enfermagem $21,1 \%$ e os Atendentes $63,8 \%$. Estas proporções variam no país conforme a região, sem alterarem-se, entretanto, substantivamente.

Vale ressaltar que temos no Brasil atualmente, em dados aproximados, 93 cursos de graduação em Enfermagem, 214 de Técnicos e 150 de Auxiliares de Enfermagem. A criação das escolas técnicas em enfermagem ocorreu em 1968 e a partir daí proliferaram, colocando uma nova categoria de enfermagem no setor. A porcentagem de pessoal de Nível Medio, Técnico e Auxiliar, cresce assim, de 4,6\% em 1956 para 27,7\% em 1983.

Chama a atenção, entretanto, a disparidade na absorção de pessoal de enfermagem no país, entre os hospitais públicos e privados. Nos hospitais públicos, os atendentes somam $44,4 \%$ enquanto que nos hospitais privados $72,6 \%$.

A porcentagem de enfermeiros é maior nos hospitais públi$\cos (12 \%)$ do que nos hospitais privados $(4,1 \%)$, bem como é maior nos públicos a porcentagem de pessoal de nível médio, técnicos e auxiliares $(43,5 \%)$ em relação ao setor privado, onde somam $23,2 \%$.

Um segundo ponto a ser destacado é a questão da situação empregatícia do pessoal de enfermagem. As condições adversas de trabalho, a má remuneração, a carga horária exaustiva e a impropriedade dos instrumentos legais de proteção social constatadas em estudo realizado em 1956, permanecem em 1983. Há distorções no mercado para pessoal qualificado, tais como a contratação de Técnicos e Auxiliares como Atendentes. Os contratos de trabalho não registram legalmente cargos de chefia exercidos por enfermeiros, nem remuneraram devidamente situações de periculosidade, insalubridade e adicionais de trabalho noturno. 
O não atendimento das reivindicações por melhores condições de trabalho pode ser explicado, em parte, pela mão-deobra excedente, principalmente em algumas categorias.

No caso de Enfermeiros, o número de profissionais formados tem ultrapassado o número de empregos criados. No estudo recente, patrocinado pelo Conselho Federal de Enfermagem 1 , foram confirmados os indícios de desemprego e subemprego de Enfermeiros. A média de egresso dos 81 cursos de graduação em enfermagem no triênio 1981-1983 é de cerca de 2.500 , representando um excedente anual de mão-deobra de aproximadamente $35 \%$.

A participação majoritária da mulher na enfermagem traz, historicamente, desvantagens nas condições de trabalho quando comparadas às características e oportunidades ocupacionais do trabalho masculino.

Em Nogueira ${ }^{3}$ encontramos um resmo destas características onde destacamos a renda proporcionalmente menor e menos oportunidades de trabalho autônomo para a mulher. Exemplificando: em 1980, a renda de 15 salários-mínimos era atingida por $25 \%$ dos profissionais de saúde do sexo masculino e por apenas $2,3 \%$ dos profissionais do sexo feminino.

Apesar das condições adversas de trabalho de pessoal de enfermagem, este constitui uma parcela significativa do contingente de recursos humanos do setor saúde e sobre ele recai a responsabilidade pela realização da maior parte das atividades de saúde prestadas à população.

O estudo realizado pelo Conselho Federal de Enfermagem confirma o descompasso entre a preparação das distintas categorias e sua absorção nas diversas modalidades assistenciais do setor saúde.

$\mathrm{Na}$ prática o enfermeiro deveria assumir funçōes de organização de serviços, responsabilizando-se inclusive pelas de planejamento, coordenação e avaliação da assistência. Entretanto, as estruturas organizacionais dos serviços de saúde o conduz a realizar um conjunto de tarefas de controle, baseado no modelo da gerência do processo de trabalho organizado segundo os princípios rígidos da Administração Científica, tais como distribuição e supervisão de pessoal não no sentido educativo, mas na cobrança imediata do que deve ser realizado na prestação de assistência, dando-lhe a falsa idéia de que o conjunto de tais tarefas compreende funções de planejamento e coordenação. A execução direta da assistência de enfermagem é portanto delegada ao pessoal auxiliar, principalmente ao atendente. Desta forma o trabalho é polarizado em dois extremos: de um lado o médico que realiza o diagnóstico e tratamento e de outro o atendente, que sem preparo qualitativo, executa o cuidado ao doente.

Neste contexto questiona-se a qualidade da assistência de enfermagem quando se observa que nem mesmo a especialização do enfermeiro em obstetrícia, pediatria, saúde pública $e$ médico-cirúrgia é utilizada no mercado de trabalho para melhorar a qualìdade desta assistência. 


\section{A FORMAÇÃO DO ENFERMEIRO}

A resolução da VIII Conferência Nacional de Saúde, visando a Reforma Sanitária, propõe um atendimento integral no que diz respeito à promoção, proteção e recuperação da saúde, implicando na humanização do atendimento com uma visão global do homem na plenitude de seus direitos de cidadão.

A formação de recursos humanos deve estar vinculada a esta premissa básica acima referida. Então, o corpo de conhecimentos que dá sustentação à enfermagem, deve abranger uma formação que assegure ao enfermeiro uma alta competência na assistência de enfermagem, no âmbito técnico-cientifico, administrativo e político. Assim, o objeto de trabalho do enfermeiro passa pela assistência de enfermagem no processo saúde-doença e se estende à organização do processo de trabalho em enfermagem, incluindo aqui um papel administrativo que lhe possibilite o bom gerenciamento da assistência prestada e ainda, uma ação conjunta com os outros profissionais da área da saúde.

A formação do enfermeiro sempre esteve muito voltada para o domínio do conhecimento técnico-científico mas, mesmo assim sendo, este não tem acompanhado o desenvolvimento tecnológico na área da saúde, devido em parte à dicotomia e distanciamento entre teoria e prática.

O corpo de conhecimento que conduz à competência técnico-científica deve levar em consideração todas as fases de desenvolvimento do homem, do nascimento à morte, na promoção, proteção e recuperação de sua saúde. Portanto, o ensino deve preparar enfermeiros tanto para atuarem no nível primário de saúde como ambulatórios e centros de saúde, como para os níveis mais complexos de assistência, como o hospitalar, com tecnologias mais especializadas.

O corpo de conhecimentos deve levar em consideração o homem brasileiro em sua realidade concreta e histórica, portanto deve considerar o homem biológico, psicológico, cultural e social.

"O papel do enfermeiro não está limitado à prestação direta de cuidados ou à supervisão de pessoal auxiliar ou ainda à administração de unidades de internação. Entende-se, como força especial às funções gerais de planejamento e administração."

Sendo imprescindível que o enfermeiro exerça funções de coordenação, ensino e supervisão, novos modelos de administração, mais condizentes coin nossa realidade, devem ser buscados. Assumir a gerência nos moldes Tayloristas o mantém distante das necessidades específicas da clientela, impede-o de interferir efetivamente, bem como não lhe permite uma visão global do setor saúde. A formação profissional do enfermeiro deve constar então de vários modelos de administração, complementada com disciplinas sobre planejamento, economia e informática, entre outros, qualificando-o para exercer com propriedade múltiplas funções, contribuindo para a implantação de uma assistência de boa qualidade em todos os níveis da assistência à saúde. 
À competência técnico-científica e administrativa, deve-se agregar a competência política, o que permitirá ao aluno o desenvolvimento de uma consciência crítica, facilitando sua ação transformadora na prática sanitária.

Tal competência política deve ser considerada nos seguintes aspectos:

- que saúde não é exclusivamente possibilitar acesso aos serviços de saúde, mas é um processo mais amplo que inclui condições de vida como trabalho, alimentação, transporte, educação, renda, lazer, etc. . .;

- que saúde é um direito de todo indivíduo e que o estado é responsável pela sua garantia;

- que a função do enfermeiro não é só assistencial, mas tem um forte componente de ação transformadora da realidade econômica e política em que atua;

- que é necessária suą participação com as outras categorias de enfermagem e outros profissionais de saúde para entender as práticas sanitárias e propor mudanças no setor;

- que o conhecimento em saúde não é monopólio de determinadas categorias profissionais, mas deve ser estendido ao pessoal auxiliar e à comunidade;

- que o enfermeiro tem grande responsabilidade no treinamento e capacitação do pessoal auxiliar de enfermagem, na garantia da qualidade da assistência;

- que o ensino de enfermagem deve se preocupar com a garantia da integração docente-assistencial, ampliando os campos de estágio para além dos hospitais de ensino tradicionais, com presença nos órgãos de decisão das políticas de saúde, tanto a nível local quanto regional;

- que na formação do enfermeiro, as questōes relativas às condiçōes de trabalho devem ser tratadas, de acordo com o registrado no Tema dois do Relatório Final da VIII Conferência Nacional de Saúde: remuneração condigna, isonomia salarial, estabelecimento de cargos e salários, criando-se carreiras não só para médicos, mas também para os demais profissionais, admissão através de concurso público e estabilidade no emprego, composição multiprofissional das equipes e compromissos dos servidores com os usuários.

A formação do enfermeiro se estende também à pós-graduação (a partir da década de 70) fazendo com que os enfermeiros, e mais especificamente aqueles que exercem a docência, ampliassem suas atividades, passando a dedicar-se à pesquisa e à produção científica. Observa-se então no ensino de enfermagem, um movimento de intelectualização, levando os enfermeiros pós-graduados a um distanciamento das demais categorias de enfermagem bem como dos serviças.

Além disso, esta produção de conhecimento não tem sido utilizada para direcionar a prática de enfermagem pois, repro-

Cadernos de Saúde Pública, R.J., 2 (4): 505-510, out/dez, 1986 
duzindo o modelo utilizado pela Escola Médica e pela Enfermagem norte-americana, não leva em conta as condições históricas socialmente deteminadas da assistência de enfermagem prestada em nossas instituições de saúde.

Ainda com relação aos cursos de pós-graduação, estes devem se preocupar com o preparo pedagogico de docentes para o ensino, além do desenvolvimento da pesquisa, para permitir uma transmissão eficaz do conhecimento.

Estas são algumas consideraçōes e reflexões levantadas sobre a formação do enfermeiro frente à Reforma Sanitária. Consideramos que o momento de transição política que ora passa o país, conclama os enfermeiros a discutirem o seu papel na equipe de saúde para viabilizar uma prática de enfermagem direcionada a todo cidadão brasileiro.

\section{BIBLIOGRAGIA CONSULTADA}

1. CONSELHO FEDERAL DE ENFERMAGEM. $O$ exercicio da enfermagem nas instituições de saúde no Brasil: 1982/1983. Rio de Janeiro, COFEn/ABEn, 1985.

2. NOGUEIRA, R.P. A política de saúde e a formação de recursos humanos. In: SEMINÁRIO A PRÁTICA E CURRÍCULO DE GRADUAÇÃO. Ribeirāo Preto, 1985. Anais. Ribeirăo Preto, CODAC/USP, 1985.

3. NOGUEIRA, R.P. Dinâmica do mercado de trabalho em saúde no Brasil, 1970/1983. Braślia, OPS, 1986. 